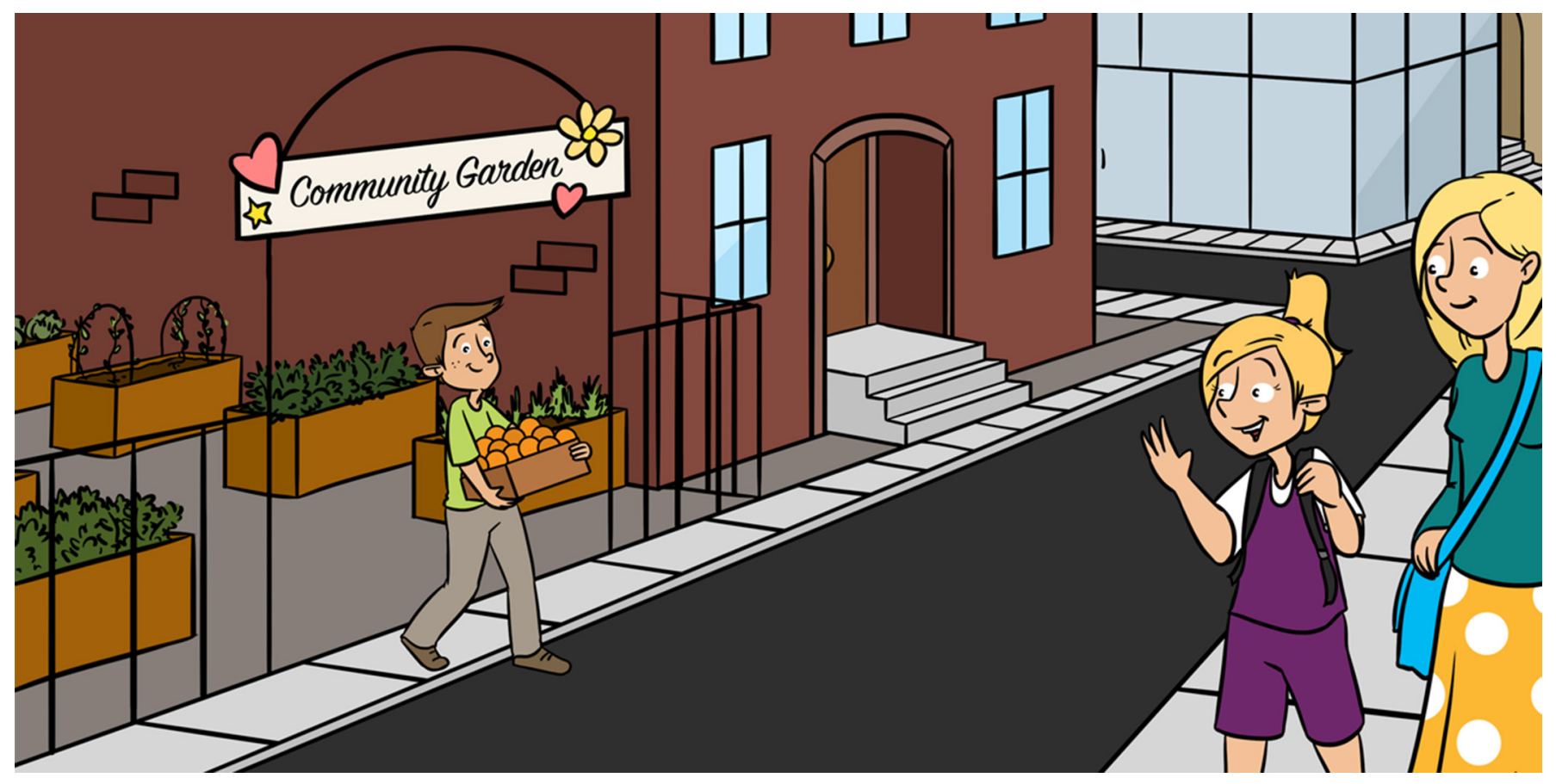

\title{
THE IMPORTANT ROLES OF URBAN AGRICULTURE
}

\section{Francesco Orsini $i^{1 *}$ and Michele D'Ostuni ${ }^{2 *}$}

${ }^{1}$ Department of Agricultural and Food Sciences (DISTAL), University of Bologna, Bologna, Italy

${ }^{2}$ Dipartimento di Architettura (DIDA), University of Florence, Florence, Italy

YOUNG REVIEWER:

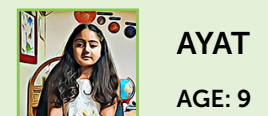

The growing urban population, climate change, and the scarcity of natural resources are major world-wide challenges. In the coming years, we must ensure that more food is available to feed Earth's growing population. We need to reduce the pressures that agriculture places on the Earth. Urban agriculture, which means growing food in cities, evolved throughout human history. Urban agriculture promotes local and sustainable food systems. Agriculture in cities is good for the environment, the ecosystem, and the climate. Urban farming brings communities together and it improves the health of citizens. There are many good reasons for farming in the city!

\section{WHEN DID URBAN AGRICULTURE BEGIN?}

The growing of plants by humans, called agriculture, started at the very beginning of civilization. After agriculture took hold, the constant movement of civilizations that was necessary for hunting and gathering was no longer needed to obtain food. Therefore, humans settled in villages. The first documented examples of urban agriculture 
Figure 1

History of

urban agriculture, from 8000 BCE (before the current era) to $2020 \mathrm{CE}$ (current era).

\section{URBAN ECOSYSTEM}

Any ecological system located within a city or other densely settled area. It can also refer to the greater ecological system that makes up an entire metropolitan area.

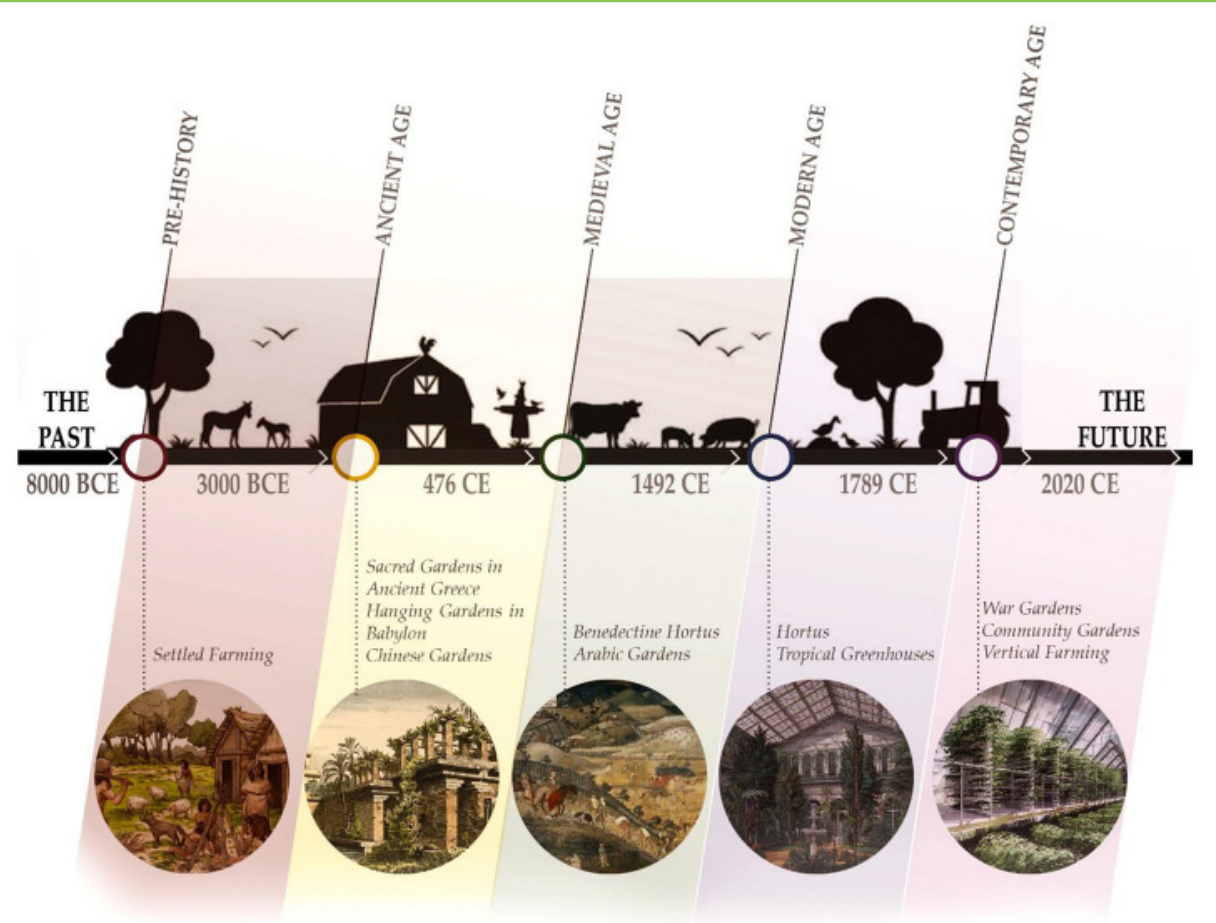

Figure 1

(the growing of food within cities) include the hanging gardens of Babylon and the sacred lands of Greek cities. The health benefits of gardening were studied in Chinese gardens more than 2,000 years ago. Similarly, Arabic gardens combined beauty with other sensory experiences, such as smells and odors from aromatic plants, flowers for visual attractiveness or sounds by including plants that would attract birds and other fauna. Gardens were often places people went for their spiritual and mental wellbeing. In the Middle Ages, kitchen gardens, called hortus, appeared. In Benedictine monasteries, food was produced and processed by monks. In the Modern Age (from late 1400), the villas of wealthiest in Northern Europe had exotic plants in their tropical glass greenhouses. During the Industrial Revolution, factory workers also started gardening. These gardens both produced fresh food and provided places for workers to relax and reduce stress. Urban gardens were also promoted during war times, to provide cities with fresh vegetables. In recent years, urban agriculture has been associated with advances in society and technology (Figure 1). We can say that agriculture has contributed to the growth and development of urban cultures throughout human history!

\section{ARE URBAN ECOSYSTEMS SUSTAINABLE?}

First, what is an urban ecosystem? An urban ecosystem includes all the living organisms and non-living components of the urban environment, and it considers all their interactions and connections. 
Figure 2

The urban ecosystem About $50 \%$ of people currently live in urban environments and this percentage will continue to grow into the future. Urban environments can have serious impacts on Earth's environment, including a large contribution to climate change and the successive abandonment of rural areas. Besides, cities cover land with an impermeable layer of concrete that limits water flows during rainfall, causing floods, and accumulate heat during warmer seasons, resulting hotter than the surrounding countryside (Urban Heat Island effect).

\section{SUSTAINABILITY}

All those practices that can guarantee that humans can

successfully provide for their needs without compromising the natural, social, and economic environments where they live.

\section{RESILIENCE}

The capacity of an ecosystem to respond to a disturbance by resisting damage and recovering quickly.

\section{SOIL SEALING}

The process that occurs when soil is covered with impermeable material (asphalt, concrete, etc.). It is an irreversible process linked to construction in cities.
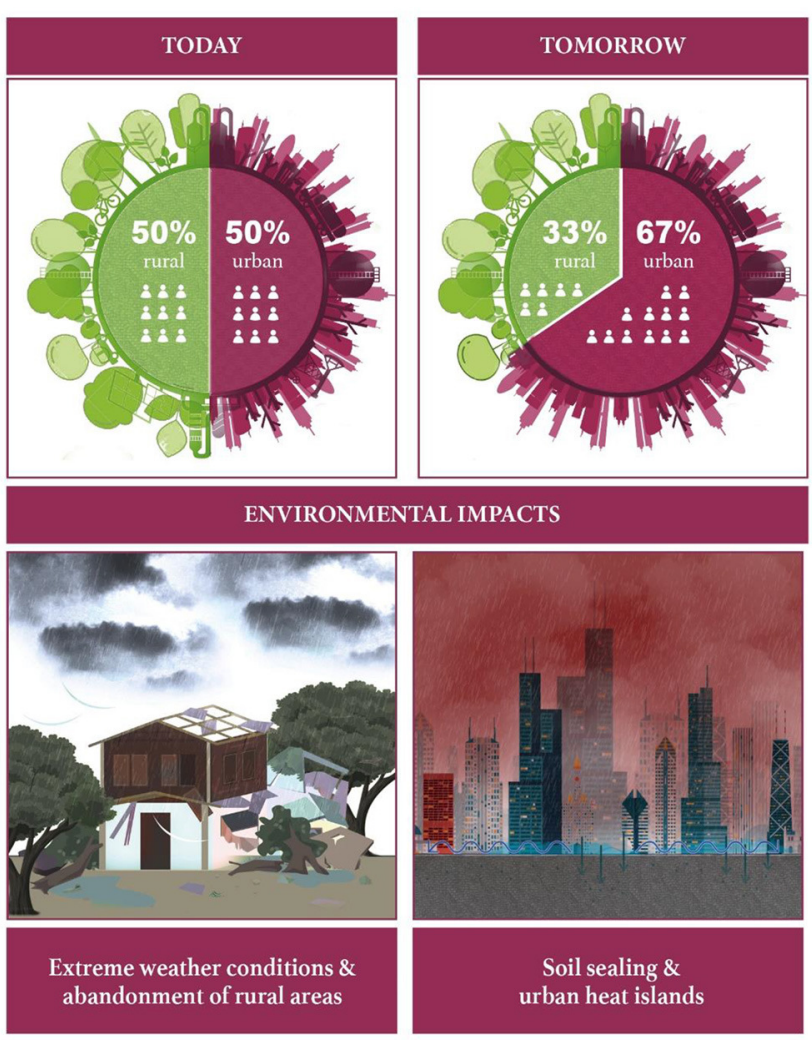

Figure 2

A sustainable ecosystem is one that allows for multiple species to live and interact in the long term.

Today, half of all people on Earth live in urban settings. By 2050, two thirds of the global population will live in cities (Figure 2). All these people will need food daily! Food for people living in cities is generally produced elsewhere-it normally comes from farmers in rural areas. When an ecosystem does not include all its necessary components, the ecosystem may be considered incomplete. An incomplete ecosystem can have a high environmental impact. For example, additional energy must be used to transport fresh food to cities and store it there. Incomplete ecosystems also have lower resilience, which means their capacity to stand stresses. For example, when a crisis occurs (such as a pandemic or a war conflict), it may be difficult for people in cities to find food.

In highly dense cities, the urban ecosystem is at risk. For example, in urban environments, much of the soil is often covered by concrete or asphalt. This is called soil sealing, and it can prevent water from being absorbed by soils. When intense rain occurs, soil sealing often results in flooded cities because the rainwater cannot enter the soils. Cities can also be significantly warmer than surrounding rural areas, due to 
Figure 3

Urban agriculture has many benefits for the climate, for city-dwelling people, and for the local ecosystem.

\section{URBAN HEAT}

ISLAND

An urban area that is significantly warmer than its surrounding rural areas due to human activities.

\section{BIODIVERSITY}

All living creatures that exist in an ecosystem. Biodiversity keeps Earth's environment in balance, so it is important to preserve it.

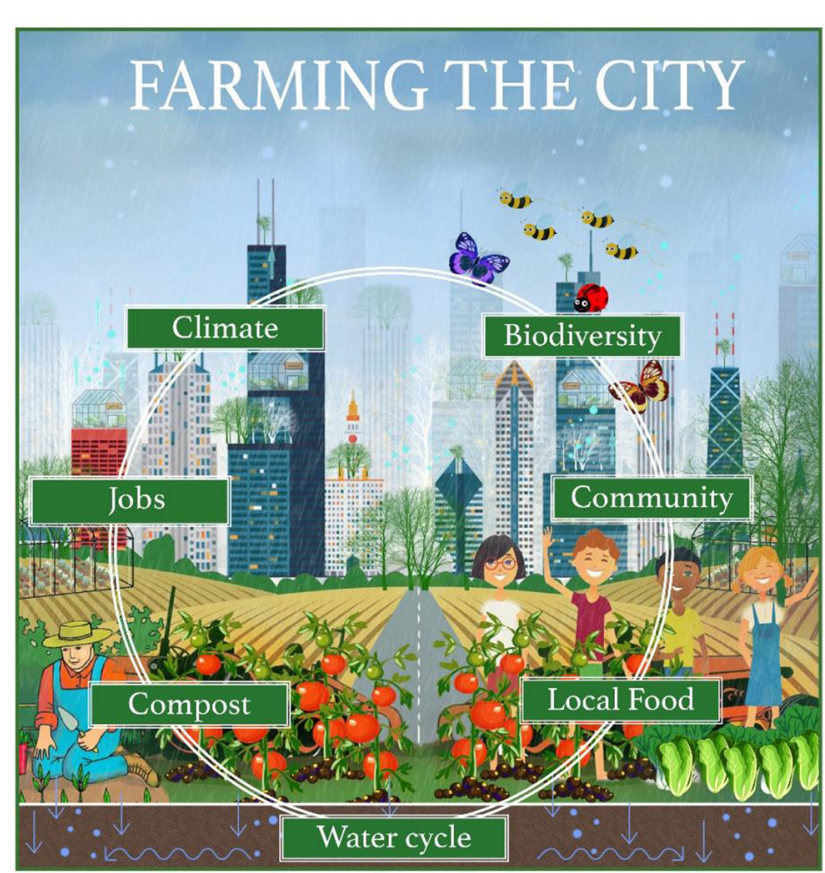

Figure 3

human activities. These warm cities are called urban heat islands. Just imagine a city as an island of heat, floating in the cool sea of the surrounding countryside!

When green spaces and parks are limited in urban environments, biodiversity is also at risk. People who live in cities generally have limited access to nature. All these factors tell us that the presence of plants within a city serves multiple functions for the urban ecosystem!

\section{CAN URBAN AGRICULTURE MAKE OUR CITIES MORE SUSTAINABLE?}

Urban farming may help with a city's environmental, social, and economic challenges. Plants can improve the Earth's climate by reducing heat during the warm season, and they can retain water during intense rains, reducing the risk of floods. Urban gardens and parks can provide shelter for birds and beneficial insects, which helps to preserve urban biodiversity. A lot of organic waste, for example fresh food residues, is produced in cities. Organic waste can be turned into compost and used in urban gardens. Also, used coffee grounds may be collected from bars and restaurants-these are great for growing mushrooms.

The health of city citizens who are involved in urban gardening often improves. These city dwellers generally have more diversified diets and eat more fruits and vegetables, which are rich in vitamins and 


\section{FOOD SECURITY}

The condition where all the population has access to a sufficient quantity of affordable, nutritious food.

\section{VERTICAL FARMS}

A building in which plants are grown in multiple layers or levels, generally supplied with artificial light. minerals. These foods are good for our health! When people engage in urban gardening, their sense of belonging to the local community is increased. Citizens benefit from meeting their neighbors and they may bond with new people. Urban agriculture may contribute greatly to a city's food security. Food security is guaranteed when all the population have sufficient access to food to satisfy their needs. Urban gardening could potentially fill a city's needs for fresh fruits and vegetables [1].

Today, urban agriculture projects are increasing worldwide, and they are creating new jobs (Figure 3). Some restaurants only use locally produced food. Other successful examples of urban agriculture include school gardens and cooking workshops that use ingredients grown in the city. Urban farms also become places where technological advances can happen. For example, plants can be grown inside closed rooms and using artificial light, as is the case for vertical farms, which are enclosed cultivation systems where plants are grown in multiple layers, supplied by artificial lighting [2]. Also, rooftop farms and greenhouses are commonly found in the cities of North America. All in all, we can say that farming in the city is a way to create a more sustainable and livable environment for the world's growing urban population!

\section{ACKNOWLEDGMENTS}

The research leading to this publication has received funding from the European Union's Horizon 2020 research and innovation programme under grant agreement No. 862663.

\section{ORIGINAL SOURCE ARTICLE}

Orsini, F., Pennisi, G., Michelon, N., Minelli, A., Bazzocchi, G., Sanyé-Mengual, E., et al. 2020. Features and functions of multifunctional urban agriculture in the global north: a review. Front. Sustain. Food Syst. 4:562513. doi: 10.3389/fsufs.2020.562513

\section{REFERENCES}

1. Orsini, F., Gasperi, D., Marchetti, L., Piovene, C., Draghetti, S., Ramazzotti, S., et al. 2014. Exploring the production capacity of rooftop gardens (RTGs) in urban agriculture: The potential impact on food and nutrition security, biodiversity and other ecosystem services in the city of Bologna. Food Sec. 6:781-92. doi: 10.1007/s12571-014-0389-6

2. Orsini, F., Pennisi, G., Zulfiqar, F., and Gianquinto, G. 2020. Sustainable use of resources in plant factories with artificial lighting (PFALs). Euro. J. Horticult. Sci. 85:297-309. doi: 10.17660/eJHS.2020/85.5.1 
SUBMITTED: 28 April 2021; ACCEPTED: 01 February 2022;

PUBLISHED ONLINE: 24 February 2022.

EDITOR: Dominik K. Großkinsky, Austrian Institute of Technology (AIT), Austria

SCIENCE MENTOR: Tahir Ali

CITATION: Orsini F and D'Ostuni M (2022) The Important Roles of Urban Agriculture. Front. Young Minds 10:701688. doi: 10.3389/frym.2022.701688

AUTHOR DISCLAIMER: The publication reflects the author's views. The Research Executive Agency (REA) is not liable for any use that may be made of the information contained therein.

CONFLICT OF INTEREST: The authors declare that the research was conducted in the absence of any commercial or financial relationships that could be construed as a potential conflict of interest.

COPYRIGHT @ 2022 Orsini and D'Ostuni. This is an open-access article distributed under the terms of the Creative Commons Attribution License (CC BY). The use, distribution or reproduction in other forums is permitted, provided the original author(s) and the copyright owner(s) are credited and that the original publication in this journal is cited, in accordance with accepted academic practice. No use, distribution or reproduction is permitted which does not comply with these terms.

\section{YOUNG REVIEWER}

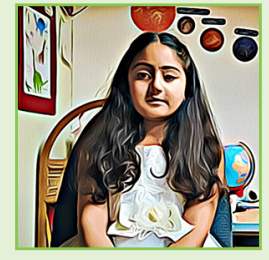

\section{AYAT, AGE: 9}

I love drawing, painting, playing chess and reading books. My favorite books include "the secret garden" and "the wonderful wizard of $\mathrm{Oz}$," and anything and everything about Dinosaurs. I like nature and frequently go out hiking to observe the beauty of nature and take notes and make sketches in my notebook.

\section{AUTHORS}

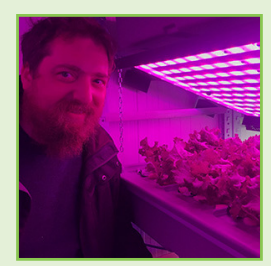

\section{FRANCESCO ORSINI}

I was always intrigued by how a traditional activity like agriculture could accept and integrate new technologies. We always think of farming as a rural activity, despite the fact that most of the world's population lives in cities, and that new technologies for growing plants in city environments are already available. After taking part in community farming projects in African, South-East Asian and Latin American cities, I started to research urban agriculture in Italy and Europe, and today I teach urban agriculture at Bologna University and coordinate research for the EU project Food Systems in European Cities (FoodE). *f.orsini@unibo.it

\section{MICHELE D'OSTUNI}

I am a Ph.D., student at the very end of my doctorate path. As an architect, I decided that my mission is to bring nature back into cities. In my own style, I 
am always looking for new technologies that can improve human life in urban environments. During this research I discovered the concept of urban agriculture, and I decided to develop my knowledge about this amazingly fascinating subject. I then became president of a non-profit organization called BiodiverCity that fosters urban farming initiatives in Europe, and I was involved in the organization of the UrbanFarm International Student Challenge. *michele.dostuni@unifi.it 